\title{
Stator-Flux-Based Vector Control of Induction Machines in Magnetic Saturation
}

\author{
Heath Hofmann, Student Member, IEEE, Seth R. Sanders, Member, IEEE, and Charles R. Sullivan, Member, IEEE
}

\begin{abstract}
In many variable-torque applications of induction machines, it is desirable to operate the machine at high flux levels, thus allowing the machine to produce higher torques. This can lead to saturation of the main flux path, introducing crosscoupling effects which can severely disrupt the performance of controllers dependent on knowledge of the machine's magnetic parameters. Stator-flux-oriented torque-control schemes need not depend on the magnetic parameters of the machine and, hence, are potentially more robust and easier to implement in magnetic saturation than rotor-flux-oriented control. In this paper, we present and analyze a stator-flux-oriented torque-control scheme. This controller only requires knowledge of the stator voltage, stator current, and stator resistance. An analytical expression for the maximum achievable torque output of the machine using a linear magnetics model is compared with values calculated using a nonlinear magnetics model incorporating saturation of the main flux path and is shown to be a good approximation at high flux levels, when the main flux path is heavily saturated. Experiments carried out on a 3-hp 1800-r/min wound-rotor induction machine show smooth operation of the control scheme at torque levels up to at least four times rated torque.
\end{abstract}

Index Terms-Induction machines, magnetic saturation, torque control.

\section{INTRODUCTION}

I NDUCTION machines are usually modeled with the assumption of linear magnetics. However, in many variabletorque applications, it is desirable to operate with the main flux path in magnetic saturation, allowing an induction machine to produce higher torque. For example, in vehicular applications, the induction machine may be sized for normal road conditions, yet it may be necessary to produce high instantaneous torque in order to overcome extreme inclines or to permit high acceleration and deceleration rates. A smaller machine may be used if its control system can operate properly during magnetic saturation.

In a standard rotor-flux-oriented control system, based on linear magnetic parameters, magnetic saturation in the machine can introduce cross-coupling effects that severely disrupt

Paper IPCSD 97-18, approved by the Industrial Drives Committee of the IEEE Industry Applications Society for presentation at the 1995 Industry Applications Society Annual Meeting, Lake Buena Vista, FL, October 8-12. This work was supported by the National Science Foundation under Grant ECS-9358284. Manuscript released for publication March 7, 1997.

H. Hofmann and S. R. Sanders are with the Department of Electrical Engineering and Computer Sciences, University of California, Berkeley, CA 94720-1772 USA (e-mail: heath@eecs.berkeley.edu; sanders@eecs.berkeley.edu).

C. R. Sullivan is with the Thayer School of Engineering, Dartmouth College, Hanover, NH 93755-8000 USA (e-mail: charles.r.sullivan@dartmouth.edu).

Publisher Item Identifier S 0093-9994(97)05460-1.

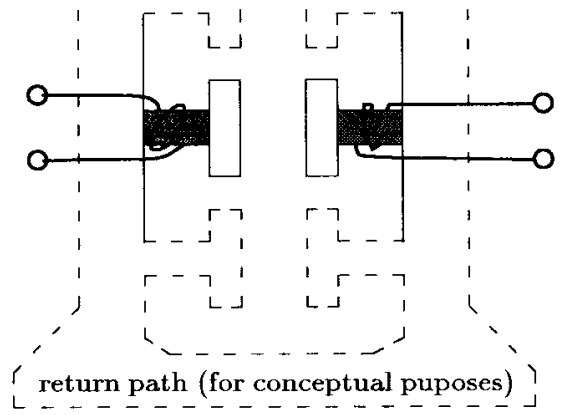

Fig. 1. Stator-rotor tooth pair.

performance [1]-[8], as well as generate errors in rotor flux estimation. Our earlier work [9] and that of others [5], [10]-[12], have shown that adequate performance can be achieved with rotor-flux-based control by incorporating knowledge of the magnetic saturation into the control law. Unfortunately, this approach requires that substantial measurements be taken on the induction machine to determine the magnetic saturation characteristics. Hence, a simpler, more robust control scheme is desired.

Stator-flux-oriented torque control has been developed as a possible alternative [13]-[24]. Estimation of the stator flux does not require knowledge of the magnetic parameters and, hence, need not be influenced by magnetic saturation. Furthermore, simple control schemes for regulation of flux and torque need not depend on the magnetic parameters. Hence, stator-flux-oriented control is potentially more robust and easier to implement in the saturation region than rotor-fluxoriented control. In this paper, we show that a particular expression for torque, the cross product of stator flux and stator current, is valid even when the induction machine is operating in magnetic saturation. We then present and analyze a control design that is independent of magnetic parameters. We also define the steady-state operating region of the control scheme using a nonlinear magnetic model for the machine which incorporates saturation of the main flux path. Finally, experiments performed on a 3-hp four-pole induction machine show smooth operation of the control scheme at torque levels up to at least four times rated torque.

\section{Magnetic Circuit Modeling}

Our state equations are based on a nonlinear $\pi$ model of the induction machine magnetic parameters developed in [25]. The model is derived from the magnetic circuit of a stator-rotor tooth pair (see Figs. 1 and 2). We assume that saturation 


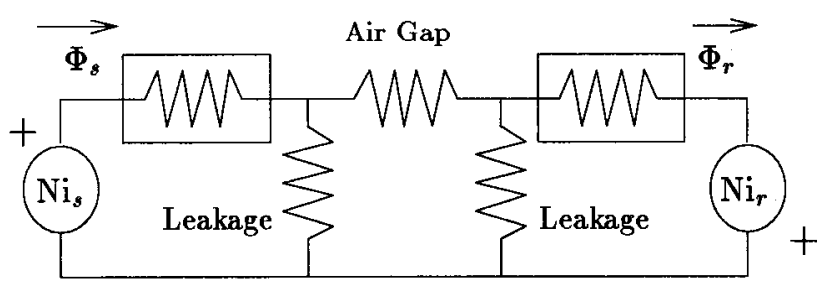

Fig. 2. Magnetic circuit of stator-rotor tooth pair. Boxed elements are nonlinear.

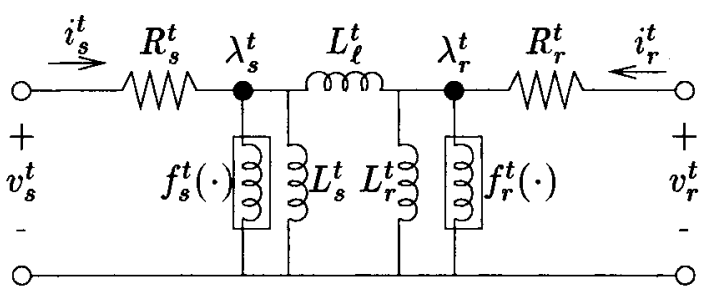

Fig. 3. Electric circuit of stator-rotor tooth pair. Boxed elements are nonlinear.

only occurs in the legs of the stator and rotor teeth. From this magnetic circuit, we can derive an electric circuit for the stator-rotor tooth pair (see Fig. 3).

The boxed inductors are nonlinear with flux-current relationships $i=f(\lambda)$. These functions account for the saturation in the stator and rotor teeth and are assumed to be singlevalued, monotonic, and to pass through the origin. Hysteresis effects are ignored, as this would require $f(\cdot)$ to have multiple values. Removal of these nonlinear inductors yields a linear model of the tooth pair.

To progress from the model of a single tooth pair to a model of a symmetric induction machine, we assume a smooth airgap. The induction machine model is obtained by summing the flux linkages of all teeth, taking into account the winding pattern of the stator and rotor to determine the effective number of turns per tooth. We assume two-phase (direct and quadrature) windings, noting that the standard transformations can be used to model a three-phase winding structure. The result is an electrical circuit equivalent in topology to that of the stator-rotor tooth pair of Fig. 3. Variables for the direct and quadrature windings are represented together in two-dimensional vector form. For example,

$$
\vec{i}_{s}=\left[\begin{array}{l}
i_{s d} \\
i_{s q}
\end{array}\right]
$$

The nonlinear inductors of the induction machine are then described by vector functions of the form $\vec{i}=F(\vec{\lambda})$. The vector direction of $\vec{i}$ is the same as the direction of $\vec{\lambda}$, and rotational symmetry implies that $\|\vec{i}\|$ depends only on $\|\vec{\lambda}\|$. As a result of these two constraints, $F(\cdot)$ may be written as

$$
F(\vec{\lambda})=f(\|\vec{\lambda}\|) \frac{\vec{\lambda}}{\|\vec{\lambda}\|}
$$

where the function $f(\cdot)$ is a scalar function that is shaped similarly to the saturation characteristic of the individual teeth, but is produced by the combination of the saturation characteristics of the steel in many teeth acting simultaneously. The current-flux relationship of the machine can then be represented as follows:

$$
\left[\begin{array}{l}
\vec{i}_{s} \\
\vec{i}_{r}
\end{array}\right]=\underline{\mathbf{L}}^{-1}\left[\begin{array}{l}
\vec{\lambda}_{s} \\
\vec{\lambda}_{r}
\end{array}\right]+\left[\begin{array}{l}
F_{s}\left(\vec{\lambda}_{s}\right) \\
F_{r}\left(\vec{\lambda}_{r}\right)
\end{array}\right]
$$

where

$$
\underline{\mathbf{L}}^{-1}=\left[\begin{array}{cc}
\left(\frac{1}{L_{s}}+\frac{1}{L_{\ell}}\right) \mathbf{I} & -\frac{1}{L_{\ell}} \mathbf{I} \\
-\frac{1}{L_{\ell}} \mathbf{I} & \left(\frac{1}{L_{r}}+\frac{1}{L_{\ell}}\right) \mathbf{I}
\end{array}\right] .
$$

Measurements performed on a 3-hp, $1800 \mathrm{r} / \mathrm{min}$ wound-rotor induction machine show close agreement with the above model [25].

It has been shown [25] that the instantaneous torque of a three-phase machine (including saturation effects) using the nonlinear $\pi$ model can be written as $\tau=\frac{3 P}{2} \frac{1}{L_{\ell}} \vec{\lambda}_{s}^{T} \mathbf{J} \vec{\lambda}_{r}$, where $P$ is the number of pole-pairs of the machine, the superscript $T$ denotes the transpose of a vector, and $\mathbf{J}$ is the orthogonal rotation matrix:

$$
\mathbf{J}=\left[\begin{array}{cc}
0 & -1 \\
1 & 0
\end{array}\right]
$$

Using the fact that $\vec{\lambda}_{s}^{T} \mathbf{J} \vec{\lambda}_{s}=\mathbf{0}$, we can derive another expression for torque:

$$
\begin{aligned}
\tau_{e} & =\frac{3 P}{2} \frac{1}{L_{\ell}} \vec{\lambda}_{s}^{T} \mathbf{J} \vec{\lambda}_{r} \\
& =\frac{3 P}{2} \vec{\lambda}_{s}^{T} \mathbf{J}\left[\left(\frac{1}{L_{s}}+\frac{1}{L_{\ell}}\right) \vec{\lambda}_{s}+F_{s}\left(\vec{\lambda}_{s}\right)-\vec{i}_{s}\right] \\
& =\frac{3 P}{2} \vec{\lambda}_{s}^{T} \mathbf{J}\left(-\vec{i}_{s}\right) \\
& =\frac{3 P}{2} \vec{i}_{s}^{T} \mathbf{J} \vec{\lambda}_{s} .
\end{aligned}
$$

The accuracy of the above expression for torque has been confirmed experimentally in [26]. We note that for squirrelcage induction machines, which often have saturable material connecting the rotor teeth at their pole faces, saturation can also occur in the rotor leakage. As shown in the Appendix, the above expression for torque is also valid under the assumption of saturable rotor leakage.

\section{TORQUE CONTROL}

We choose the stator-flux and rotor-flux vectors as the states in our system, with the stator current vector as the output. The state equations in an arbitrary reference frame (superscript $x$ ) are then given by (see [9], [25])

$$
\left[\begin{array}{c}
\dot{\overrightarrow{\lambda_{s}^{x}}} \\
\overrightarrow{\lambda_{r}^{x}}
\end{array}\right]=\left[\begin{array}{c}
-\dot{\rho} \mathbf{J}{\overrightarrow{\lambda_{s}^{x}}}_{s} \\
-\left(\dot{\rho}-P \omega_{r}\right) \mathbf{J}{\overrightarrow{\lambda_{r}^{x}}}^{x}
\end{array}\right]-\underline{\mathbf{R}}\left[\begin{array}{c}
\vec{i}_{s}^{x} \\
\vec{i}_{r}^{x}
\end{array}\right]+\left[\begin{array}{c}
\vec{v}_{s}^{x} \\
0
\end{array}\right]
$$


where

$$
\underline{\mathbf{R}}=\left[\begin{array}{cc}
R_{s} \mathbf{I} & 0 \\
0 & R_{r} \mathbf{I}
\end{array}\right]
$$

and $\omega_{r}$ is the angular velocity of the rotor.

The variable $\rho$ represents the reference angle upon which the state equations are based. The stationary reference frame (superscript $s$ ) corresponds to $\rho=\dot{\rho}=0$, and the electrical reference frame with respect to the stator flux (superscript $e$ ) corresponds to $\rho=\angle \vec{\lambda}_{s}^{s}$. In this case, $\dot{\rho}=\omega_{e}$, the electrical frequency.

By choosing the stator flux angle as our reference frame, we set $\lambda_{s d}^{e}=\left\|\lambda_{s}\right\|$ and $\lambda_{s q}^{e}=\dot{\lambda}_{s q}^{e}=0$. Hence, in the stator flux reference frame, (29) is written as

$$
\tau_{e}=\frac{3 P}{2} \lambda_{s d}^{e} i_{s q}^{e}
$$

Constraining $\dot{\lambda}_{s q}^{e}=0$ in (6) yields an expression for the electrical frequency:

$$
\omega_{e}=\frac{v_{s q}^{e}-R_{s} i_{s q}^{e}}{\lambda_{s d}^{e}}
$$

Using this information, we rewrite the state equations in the stator flux reference frame, considering only direct stator flux and quadrature stator current dynamics:

$$
\begin{aligned}
\dot{\lambda}_{s d}^{e}= & -R_{s} i_{s d}^{e}+v_{s d}^{e} \\
\dot{i}_{s q}^{e}= & \frac{1}{L_{l}}\left[-\omega \lambda_{r d}^{e}+\frac{\lambda_{r d}^{e}}{\lambda_{s d}^{e}}\left(v_{s q}^{e}-R_{s} i_{s q}^{e}\right)\right] \\
& -R_{r}\left(\frac{1}{L_{r}}+\frac{1}{L_{l}}\right) i_{s q}^{e}-R_{r} \frac{f_{r}\left(\left\|\lambda_{r}\right\|\right)}{\left\|\lambda_{r}\right\|} i_{s q}^{e} .
\end{aligned}
$$

These equations suggest that torque can be controlled by using $v_{s d}^{e}$ to control $\lambda_{s d}^{e}$ and $v_{s q}^{e}$ to control $i_{s q}^{e}$. After compensating for the resistive voltage drop $R_{s} \vec{i}_{s}^{e}$, we may apply proportional-integral (PI) control:

$$
\begin{aligned}
v_{s d}^{e} & =R_{s} i_{s d}^{e}+K_{\lambda p} e_{\lambda}+K_{\lambda i} \int e_{\lambda}^{e} d t \\
v_{s q}^{e} & =R_{s} i_{s q}^{e}+K_{i p} e_{i}^{e}+K_{i i} \int e_{i} d t \\
e_{\lambda} & =\tilde{\lambda}_{s d}^{e}-\hat{\lambda}_{s d}^{e} \\
e_{i} & =\tilde{i}_{s q}^{e}-i_{s q}^{e}
\end{aligned}
$$

where $\tilde{\lambda}_{s d}^{e}$ and $\tilde{i}_{s q}^{e}$ correspond to commanded values and $\hat{\lambda}_{s d}^{e}$ is the estimated or measured stator flux. Although other control schemes may be used, we begin with PI control, due to its simplicity. by

With this control scheme, the stator flux dynamics are given

$$
\dot{\lambda}_{s d}^{e}=K_{\lambda p} e_{\lambda}+K_{\lambda i} \int e_{\lambda} d t
$$

Hence, stator flux can be regulated, provided the estimated or measured stator flux is in good agreement with its actual value. Furthermore, the term $R_{s} i_{s d}^{e}$ has decoupled the stator flux dynamics from the other system dynamics.

In application, $R_{s}$ can change with temperature and, therefore, it is difficult to exactly cancel the resistive voltage drop. However, this error can be considered as a small disturbance and should not seriously affect the control if sufficient gain is prescribed.

As the dynamics of $i_{s q}^{e}$ in the stator flux reference frame are nonlinear (even if linear magnetic parameters are assumed), we begin by linearizing them with respect to a steady-state operating point, in order to guide the control design. We characterize the steady-state operating point by the slip frequency $\omega_{s}=\omega_{e}-\omega_{r}$ and by the stator flux magnitude $\tilde{\lambda}_{s d}^{e}$. Since the stator flux dynamics have been decoupled from the rest of the system, we consider the stator flux magnitude to be constant as we perform the linearization. Finally, we define $\bar{v}_{s q}^{e}=v_{s q}^{e}-R_{s} i_{s q}^{e}$. The transfer function between $i_{s q}^{e}$ and $\bar{v}_{s q}^{e}$ in the linearized system can be shown to be

$$
\begin{aligned}
H(s) & =\frac{I_{s q}^{e}(s)}{\bar{V}_{s q}^{e}(s)} \\
& =\frac{R_{r}}{L_{l}^{2}\left[\Omega_{r}^{2}+\omega_{s}^{2}\right]} \cdot \frac{\Omega_{r} s+\Omega_{r}^{2}-\omega_{s}^{2}}{s^{2}+2 \Omega_{r} s+\left(\Omega_{r}^{2}+\omega_{s}^{2}\right)}
\end{aligned}
$$

where $\Omega_{r}=R_{r}\left(\frac{1}{L_{r}}+\frac{1}{L_{l}}\right)$. We calculate this frequency to be $160 \mathrm{rad} / \mathrm{s}$ for a 3 -hp induction machine.

Inspection of (16) reveals that, as the magnitude of $\omega_{s}$ increases, the zero of $H(s)$ moves from the complex lefthalf plane to the complex right-half plane at the critical slip frequencies:

$$
\omega_{s \text { crit }}= \pm \Omega_{r} .
$$

This corresponds to a change in the sign of the dc gain of the transfer function. Although this potentially increases controller complexity, we will show in Section IV that all useful operating points correspond to a zero location in the complex left-half plane.

\section{TORQUE LIMITS}

We will now show that $\omega_{s \text { crit }}$ defines a maximum possible torque magnitude that can be achieved for a given stator flux magnitude. In order to gain more insight, we analyze the steady-state stator current as a function of stator flux magnitude and slip frequency. Explicit expressions are difficult in the case of nonlinear magnetic parameters, but are readily derived if linear magnetic parameters are assumed:

$$
\begin{aligned}
& i_{s d}^{e}=\left[\left(\frac{1}{L_{l}}+\frac{1}{L_{s}}\right)-\frac{\frac{R_{r}}{L_{l}^{2}} \Omega_{r}}{\Omega_{r}^{2}+\omega_{s}^{2}}\right] \lambda_{s d}^{e}, \\
& i_{s q}^{e}=\frac{\frac{R_{r}}{L_{l}^{2}} \omega_{s}}{\Omega_{r}^{2}+\omega_{s}^{2}} \lambda_{s d}^{e} .
\end{aligned}
$$

Plots of the locus of steady-state currents assuming both linear and nonlinear magnetic parameters for a stator flux magnitude of $1 \mathrm{~V} \cdot \mathrm{s}$ are provided in Fig. 4. The parameters 


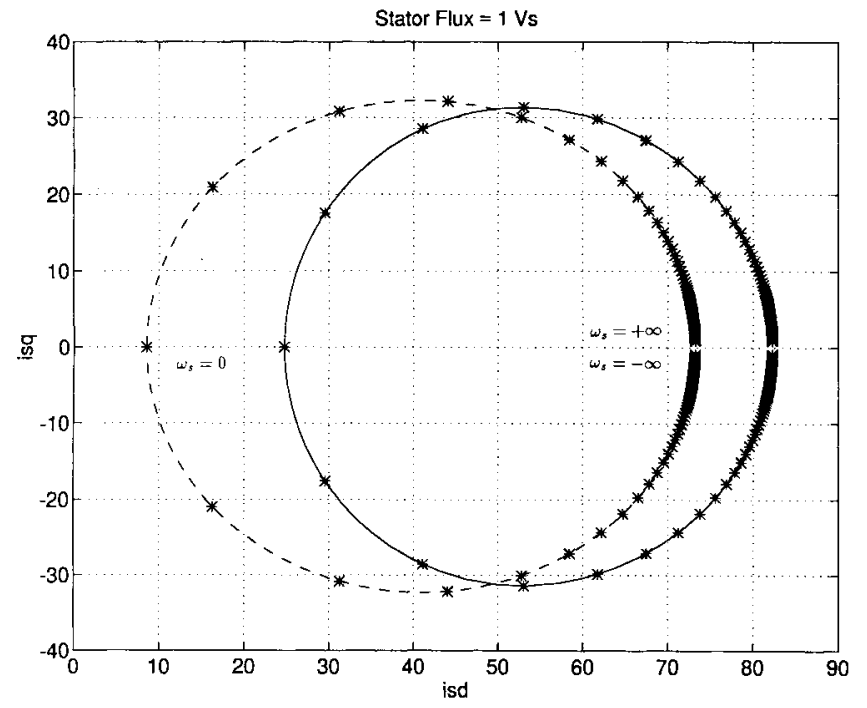

Fig. 4. Steady-state stator current as a function of slip frequency, $\tilde{\lambda}_{s d}^{e}=1$ $\mathrm{V} \cdot \mathrm{s}$, typical motor parameters. Solid line indicates nonlinear magnetics, dashed line indicates linear magnetics. Each * corresponds to $50 \mathrm{rad} / \mathrm{s}$ of slip frequency.

used in these plots (and all subsequent data) are based on measurements performed on a 3-hp four-pole wound-rotor induction machine [9], [25]. This machine has a rated flux of approximately $0.5 \mathrm{~V} \cdot \mathrm{s}$. It can be shown that, for a given stator flux magnitude, $i_{s q}^{e}$ reaches its maximum magnitude at a slip frequency equal to $\omega_{s \text { crit }}$. Hence, $\omega_{s \text { crit }}$ can and should be avoided by limiting the commanded value of $i_{s q}^{e}$ to be less than its maximum possible value, as dictated by $\lambda_{s d}^{e}$.

For a given stator flux magnitude, a maximum value of current $i_{s q \max }^{e}$ corresponds to a maximum possible torque. If linear magnetic parameters are assumed, the maximum possible torque can be determined using $\tau=\lambda_{s d}^{e} i_{s q}^{e} \max$, where $i_{s q \text { max }}^{e}$ is determined by inserting $\omega_{s}$ crit into (19). The result is

$$
\tau_{\max }=\frac{3 P}{4} \frac{L_{r}}{L_{l}\left(L_{l}+L_{r}\right)}\left\|\lambda_{s}\right\|^{2} .
$$

Equation (20) can be shown to be equivalent to the formula presented in [13], which uses a $T$ model for the motor magnetics. In general, $L_{r} \gg L_{l}$, and so we can approximate (20) with

$$
\tau_{\max } \approx \frac{3 P}{4} \frac{1}{L_{l}}\left\|\lambda_{s}\right\|^{2} .
$$

We now develop an expression for determining the maximum possible torque in the nonlinear magnetics case. To do this, we first consider another expression for torque:

$$
\begin{aligned}
\tau & =\frac{3 P}{2} \frac{1}{L_{l}} \vec{\lambda}_{s}^{T} \mathbf{J} \vec{\lambda}_{r} \\
& =\frac{3 P}{2} \frac{1}{L_{l}} \sqrt{\left\|\lambda_{r}\right\|^{2}\left\|\lambda_{s}\right\|^{2}-\left(\vec{\lambda}_{s}^{T} \vec{\lambda}_{r}\right)^{2}}
\end{aligned}
$$

assuming positive torque. By shifting into the rotor flux reference frame it can be seen that, in steady state,

$$
\vec{\lambda}_{s}^{T} \vec{\lambda}_{r}=\left\|\lambda_{r}\right\| L_{l}\left[\left(\frac{1}{L_{r}}+\frac{1}{L_{l}}\right)\left\|\lambda_{r}\right\|+f_{r}\left(\left\|\lambda_{r}\right\|\right)\right] .
$$

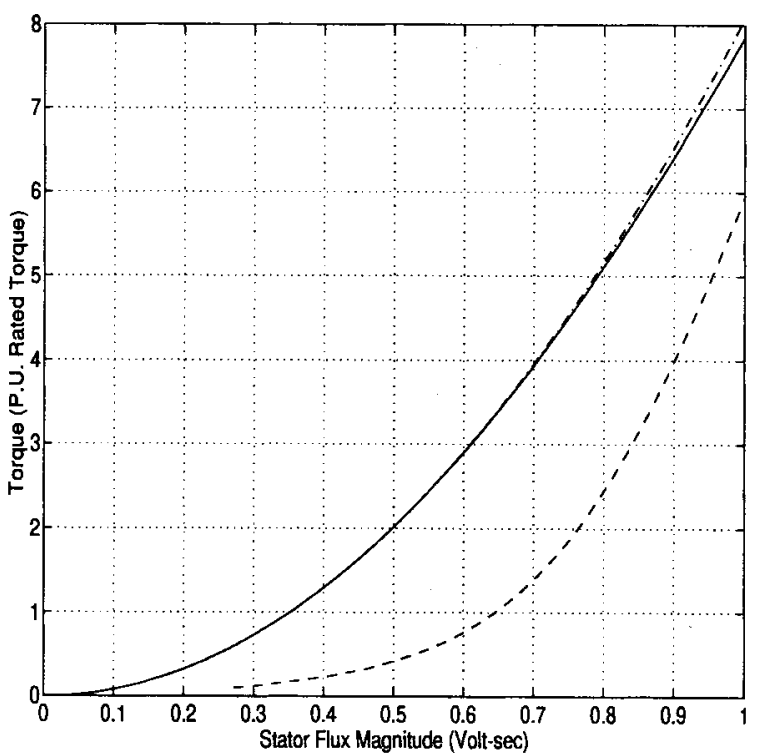

Fig. 5. Torque versus stator flux magnitude. The solid line indicates the maximum possible torque for a given stator flux magnitude assuming nonlinear magnetic parameters, the dashdot line indicates maximum allowable torque assuming linear magnetic parameters, and the dashed line indicates optimal efficiency operating points with respect to minimized rotor and stator conduction losses (nonlinear magnetics).

Combining (22) and (23) yields an expression for steady-state torque as a function of stator and rotor flux magnitudes:

$$
\begin{aligned}
\tau= & \frac{3 P}{2}\left\|\lambda_{r}\right\| \\
& \bullet \sqrt{\left(\frac{\left\|\lambda_{s}\right\|}{L_{l}}\right)^{2}-\left[\left(\frac{1}{L_{r}}+\frac{1}{L_{l}}\right)\left\|\lambda_{r}\right\|+f_{r}\left(\left\|\lambda_{r}\right\|\right)\right]^{2}} .
\end{aligned}
$$

This expression can be used to determine the maximum possible torque for a given stator flux magnitude by maximizing over $\left\|\lambda_{r}\right\|$, as shown in Fig. 5.

Fig. 5 shows the maximum possible torque versus stator flux magnitude assuming both linear and nonlinear magnetic parameters, as well as a plot of optimal-efficiency operating points. The optimal-efficiency operating points are determined by fixing torque and calculating the stator flux magnitude which minimizes rotor and stator conduction losses. We do this assuming nonlinear magnetic parameters. Notice that, for all reasonable torque levels, the optimal-efficiency operating point is well separated from the maximum allowable torque and, thus, a substantial safety margin exists for stable operation at the optimal-efficiency operating point. Notice also the close agreement between maximum torque values in the linear and nonlinear magnetics cases.

\section{IMPLEMENTATION}

A block diagram of our implementation of the control law is shown in Fig. 6. The stator flux is estimated by numerically integrating stator voltage minus resistive drop. We integrate using the third-order Adams-Bashforth method, which provides substantially higher accuracy than Euler's method [27]. A decay term is added to make the observer asymptotically stable. This limits the low-frequency performance of the drive. 


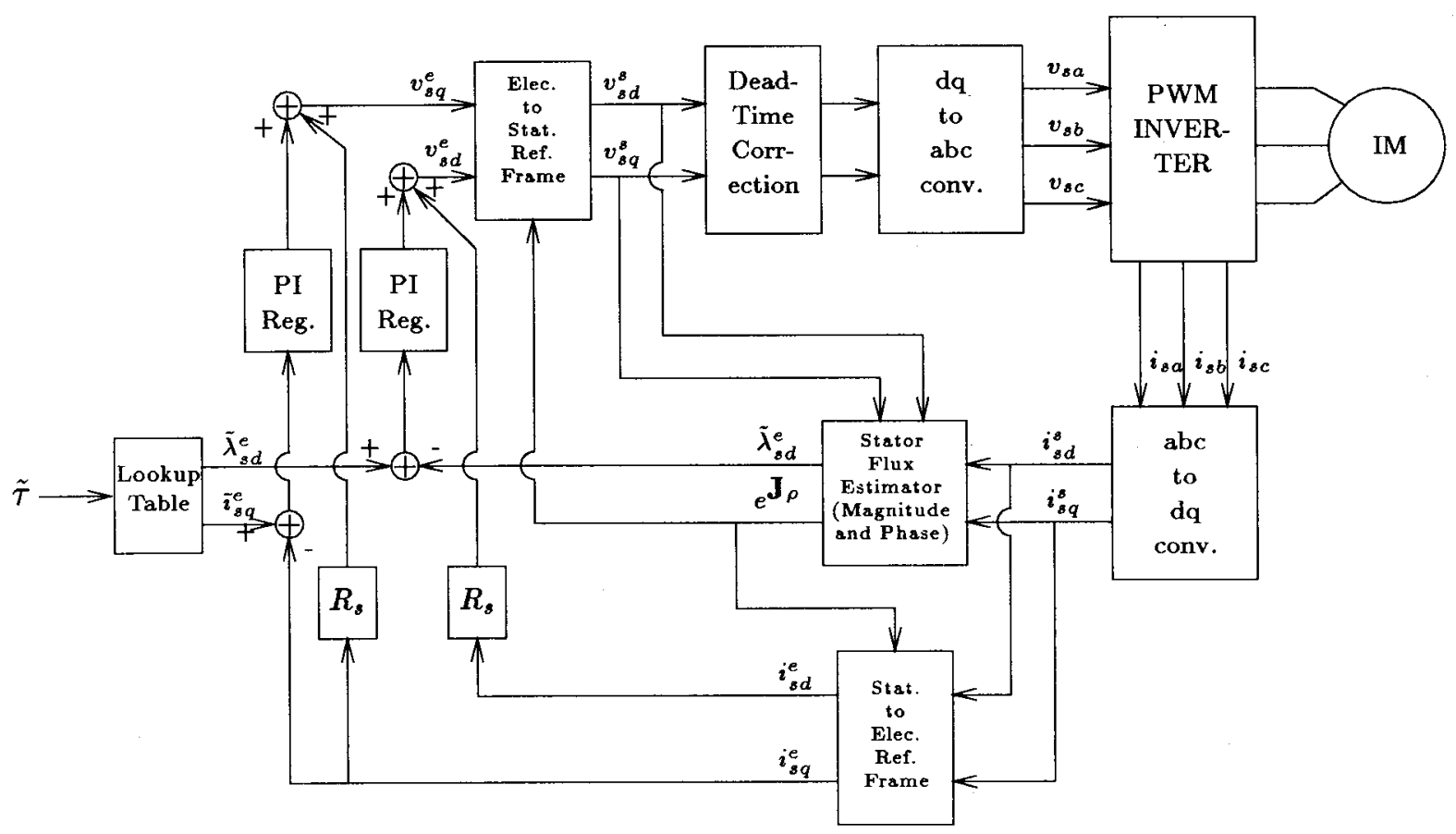

Fig. 6. Control scheme.

Results show a practical lower limit for this type of system is about $3 \mathrm{~Hz}$. However, with separate coils used for sensing flux, systems have been reported to work well at frequencies above $0.5 \mathrm{~Hz}$ [28].

The deadtime correction block is an attempt to counteract the voltage error caused by the deadtime in the inverter, or $\Delta v=-V_{\text {dead }} \operatorname{sgn}(i)$ where $V_{\text {dead }}=V_{\mathrm{DC}} f_{s} t_{\text {dead }}$ is the product of the dc bus voltage, the switching frequency, and the inverter dead time, respectively, and $i$ is the current in one phase of the inverter. We attempt to cancel the fundamental component of this voltage by subtracting it from $\vec{v}_{s}^{s}$. This technique is motivated by the describing function method and has been reported to be effective in [29].

Appropriate stator flux and quadrature stator current values for a specified torque command are referenced via a lookup table. This lookup table is best implemented with some characterization of the machine. Although instantaneous torque control as described in Section III does not require the machine magnetic characteristics, these characteristics may be used advantageously in the construction of the lookup table.

\section{EXPERIMENTAL SETUP}

The setup as described in the following is shown in Fig. 7. The motor used in our experiments is a four-pole wound rotor induction machine, rated at $3 \mathrm{hp} 1800 \mathrm{r} / \mathrm{min}$, and $220 \mathrm{~V}$ line-to-line. The motor is driven by a commercial pulsewidthmodulated (PWM) insulated-gate-bipolar-transistor (IGBT) inverter, rated at $36 \mathrm{~A}$ and $460 \mathrm{~V}$ line-to-line. Hall-effect sensors within the inverter are used to measure stator current. The microprocessor control provided in the inverter was replaced with custom hardware that directly accesses the gate drive modules. The custom hardware consists of a three-phase $15-\mathrm{kHz}$ PWM modulator that interfaces with two-

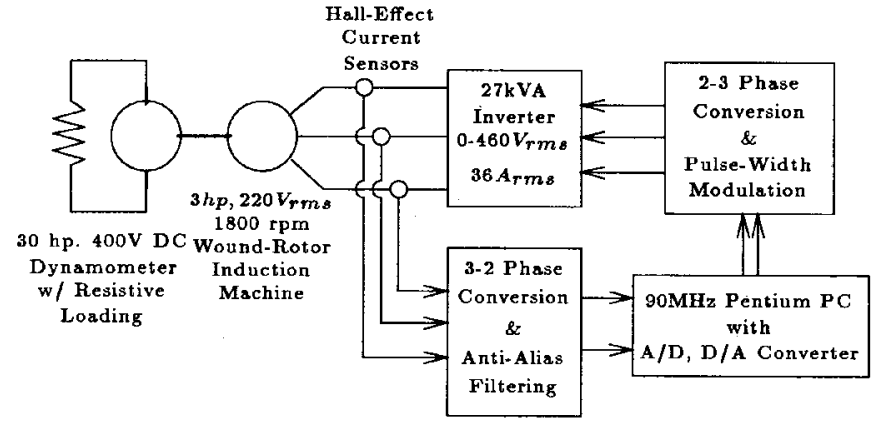

Fig. 7. Experimental setup.

axis command voltages supplied by our digital controller, a Pentium-based personal computer (PC).

The PC controller is capable of sampling stator current and updating commanded stator voltage at a sampling frequency of $10 \mathrm{kHz}$. The stator currents are filtered using two-pole Butterworth filters with a corner frequency of $210 \mathrm{~Hz}$. This presents an upper limit to the achievable bandwidth of the control.

Command torque and flux levels can be preprogrammed or changed in real time from the keyboard of the PC. Command voltages, stator currents, and estimated flux can be displayed in real time on the computer monitor or saved on the computer's hard drive.

A 40-kW separately excited dynamometer provides loading for the induction motor.

\section{EXPERIMENTAL RESULTS}

Fig. 8 shows the results of an experiment in which the induction motor was commanded with a torque step from rated torque to four times rated torque. Bandwidths of $200 \mathrm{rad} / \mathrm{s}$ and 


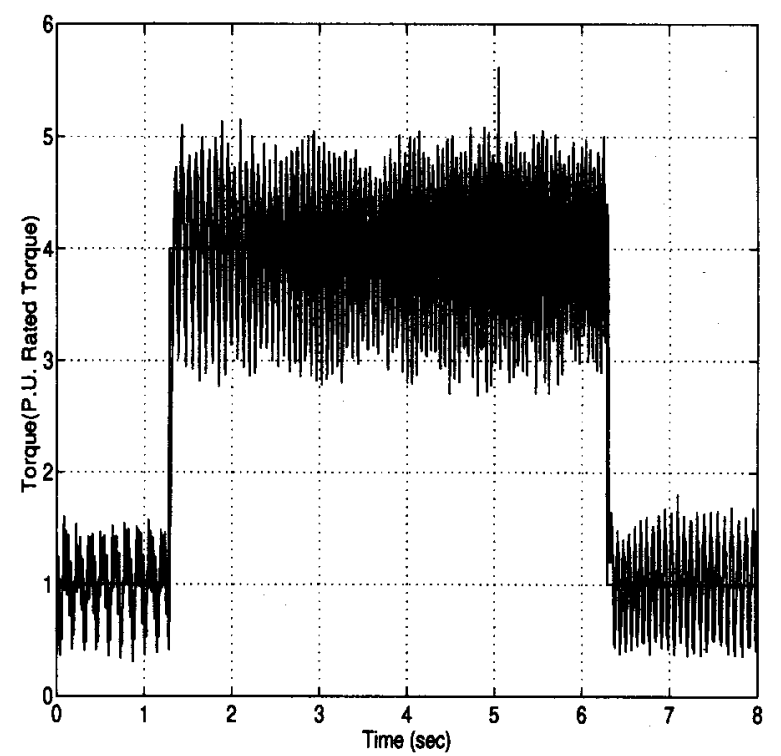

Fig. 8. Torque step from $1 x$ to $4 x$ rated torque. Experiment performed on a 3-hp 1800-r/min wound-rotor induction motor using an IBM-compatible PC to implement the control law.

$100 \mathrm{rad} / \mathrm{s}$ were used to regulate $\lambda_{s d}^{e}$ and $i_{s q}^{e}$, respectively. The low-frequency corner of the stator flux estimator $\left(K_{0}\right)$ was set at $10 \mathrm{rad} / \mathrm{s}$.

\section{CONCLUSION}

A stator-flux-based control scheme that is independent of the motor magnetic parameters has been presented. The scheme has been shown to perform well in the saturation region, allowing commanded torques up to at least four times the rated torque of the machine. Furthermore, the maximum torque level for a given stator flux magnitude is established. This torque limit is shown to be closely approximated by the linear magnetics model at high flux levels, where there is a significant safety margin between this limit and optimal operating points.

\section{APPENDIX}

\section{Torque Calculation with Saturating Rotor Leakage}

In order to derive an expression for torque for the case of nonlinear rotor leakage, we create a nonlinear electrical circuit model from the magnetic circuit of a stator-rotor tooth pair, as shown in Figs. 9 and 10. Boxed elements represent reluctances that possibly have a nonlinear flux-MMF relationship due to magnetic saturation. We will assume that saturation can occur in the legs of the stator and rotor teeth and in the leakage between the rotor teeth.

Starting with the nonlinear magnetic circuit model, we proceed with a series of transformations to achieve our electrical circuit model. We first take the dual of the magnetic circuit of Fig. 10, as shown in Fig. 11. In the dual circuit, flux is the across variable and MMF is the through variable. By performing the appropriate scaling with the number of effective turns $N_{s}$ and $N_{r}$, we can transform the flux and MMF variables into flux linkage and current variables, respectively. Differentiating the flux linkage variables with respect to time yields an electrical circuit model, as shown in Fig. 12, where

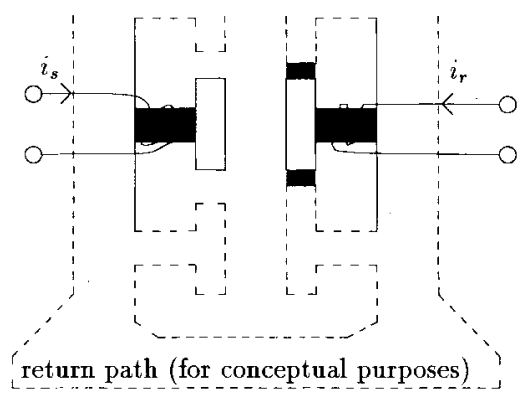

Fig. 9. Stator-rotor tooth pair including saturable rotor leakage.

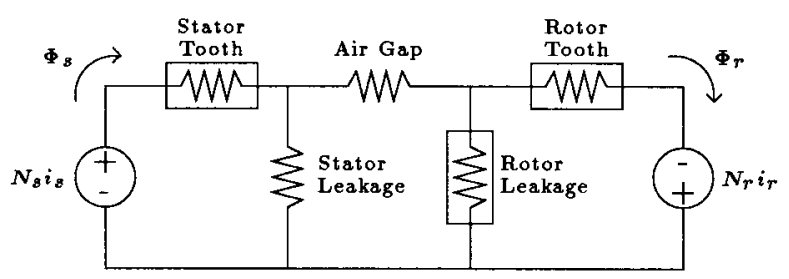

Fig. 10. Magnetic circuit of stator-rotor tooth pair. Boxed elements are nonlinear.

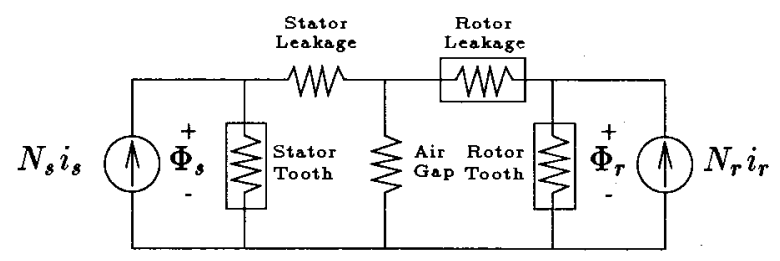

Fig. 11. Dual circuit of Fig. 10.

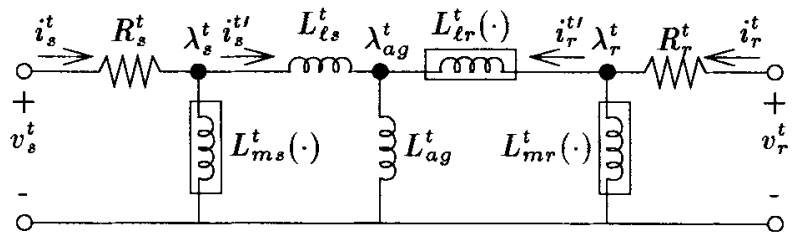

Fig. 12. Electric circuit of stator-rotor tooth pair. Boxed elements are nonlinear.

the reluctances are replaced by inductors and the resistances of the stator and rotor conductors $R_{s}$ and $R_{r}$ are included. The nonlinear inductors have inductances $L(\cdot)$, which are functions of the flux magnitude, such that $i=\frac{\lambda}{L(|\lambda|)}$.

The resulting circuit model for the symmetric induction machine is equivalent in topology to that shown in Fig. 12, with two-component (direct and quadrature) current and flux vectors as the variables. The flux-current relationship for the nonlinear inductors can be written in the following form:

$$
\vec{i}=\frac{\vec{\lambda}}{L(\|\vec{\lambda}\|)}
$$

To account for the rotor being mechanically located at an angle $\theta$, the rotor quantities are premultiplied by $e^{\mathbf{J} \theta}$.

We calculate torque by differentiating coenergy with respect to rotor angle $\theta$. To simplify analysis, we calculate the coenergy only in the airgap inductance $L_{\mathrm{ag}}$, as the coenergies in the 
leg and leakage inductances are independent of rotor angle:

$$
W^{\prime}=\frac{1}{2} L_{\mathrm{ag}}\left[\left\|\overrightarrow{\vec{i}_{s}^{\prime}}\right\|^{2}+2{\overrightarrow{i_{s}}}^{T}\left(e^{\mathbf{J} \theta} \vec{i}_{r}^{\prime}\right)+\left\|\overrightarrow{\vec{i}_{r}^{\prime}}\right\|^{2}\right] .
$$

The electromagnetic torque is then given by

$$
\begin{aligned}
\tau_{e} & =\frac{\partial W^{\prime}\left(\vec{i}_{s}^{\prime}, \vec{i}_{r}^{\prime}, \theta\right)}{\partial \theta} \\
& =\vec{i}_{s}^{T} \mathbf{J} e^{\mathbf{J} \theta} \vec{i}_{r^{\prime}}^{\prime}
\end{aligned}
$$

We now show that $\vec{i}_{s}^{T} \mathbf{J} \vec{\lambda}_{s}$ is also a valid expression for torque in the nonlinear magnetics case:

$$
\begin{aligned}
& \vec{i}_{s}^{T} \mathbf{J} \vec{\lambda}_{s}=\left(\vec{i}_{s}^{\prime}+\vec{i}_{s}-\vec{i}_{s}\right)^{T} \mathbf{J} \vec{\lambda}_{s} \\
& =\left[\vec{i}_{s}^{\prime}+\frac{\vec{\lambda}_{s}}{L_{m s}\left(\left\|\vec{\lambda}_{s}\right\|\right)}\right]^{T} \mathbf{J} \vec{\lambda}_{s} \\
& =\vec{i}_{s}^{T} \mathbf{J} \vec{\lambda}_{s} \\
& =\vec{i}_{s}^{T} \mathbf{J}\left[L_{\ell s} \vec{i}_{s}^{\prime}+L_{\mathrm{ag}}\left(\vec{i}_{s}^{\prime}+e^{\mathbf{J} \theta} \vec{i}_{r}^{\prime}\right)\right] \\
& =\vec{i}_{s}^{T} \mathbf{J} e^{\mathbf{J} \theta} \vec{i}_{r} \\
& =\tau_{e} \text {. }
\end{aligned}
$$

For a three-phase machine with $P$ pole-pairs, the torque equation becomes

$$
\tau_{e}=\frac{3 P}{2} \vec{i}_{s}^{T} \mathbf{J} \vec{\lambda}_{s}
$$

Hence, the above expression for torque is valid, even in the case of saturable rotor leakage.

\section{REFERENCES}

[1] J. E. Brown, K. P. Kovacs, and P. Vas, "A method of including the effects of main flux path saturation in the generalized equations of A.C. machines," IEEE Trans. Power App. Syst., vol. PAS-102, pp. 96-103, Jan. 1983.

[2] P. Vas, K. E. Hallenious, and J. E. Brown, "Cross-saturation in smoothair-gap electrical machines," IEEE Trans. Energy Conversion, vol. EC-1, pp. 103-109, Mar. 1986.

[3] R. J. Kerkman, "Steady-state and transient analysis of an induction machine with saturation of the magnetizing branch," IEEE Trans. Ind. Applicat., vol. IA-21, pp. 226-234, Jan./Feb. 1985.

[4] M. S. Garrido, L. Pierrat, and E. Dejaeger, "The matrix analysis of saturated electrical machines," in Modeling and Simulation of Electrical Machines and Power Systems, J. Robert and D. K. Tran, Eds. Amsterdam, The Netherlands: Elsevier, 1988, pp. 137-144.

[5] P. Vas, Vector Control of AC Machines. London, U.K.: Oxford Univ. Press, 1990.

[6] R. D. Lorenz and D. W. Novotny, "Saturation effects in field-oriented induction machines," IEEE Trans. Ind. Applicat., vol. 26, pp. 283-289, Mar./Apr. 1990.

[7] F. M. H. Khater, R. D. Lorenz, D. W. Novotny, and K. Tang, "Saturation effects in field-oriented induction machines," IEEE Trans. Ind. Applicat., vol. IA-23, pp. 276-282, Mar./Apr. 1987.

[8] P. Vas and M. Alakula, "Field-oriented control of saturated induction machines," IEEE Trans. Energy Conversion, vol. 5, pp. 218-223, Mar. 1990.

[9] C. R. Sullivan, C. Kao, B. M. Acker, and S. R. Sanders, "Control systems for induction machines with magnetic saturation," IEEE Trans. Ind. Electron., vol. 43, pp. 142-152, Feb. 1996.

[10] E. Levi, S. Vukosavic, and V. Vuckovic, "Saturation compensation schemes for vector controlled induction motor drives," in Conf. Rec. PESC'90, 1990, pp. 591-598.

[11] E. Levi and V. Vuckovic, "Field-oriented control of induction machines in the presence of magnetic saturation," Elec. Mach. Power Syst., vol. 16, no. 2, pp. 133-147, 1989.
[12] Z. Krzeminski, "Differential equations of induction motor with nonlinear control synthesis with regard to saturation of main magnetic path," Rozpr. Electrotech., vol. 34, no. 1, pp. 117-131, 1988.

[13] X. Xu, R. D. Doncker, and D. W. Novotny, "A stator flux oriented induction machine drive," in Conf. Rec. 19th Annu. IEEE Power Electronics Specialists Conf., 1988, pp. 870-876.

[14] E. Mendes and A. Razek, "A simple model for core losses and magnetic saturation in induction machines adapted for direct stator flux orientation control," in Proc. 5th Int. Conf. Power Electronics and Variable-Speed Drives, 1993, pp. 444-449.

[15] X. Xu and D. Novotny, "Implementation of direct stator flux orientation on a versatile dsp-based system," IEEE Trans. Ind. Applicat., vol. 27, pp. 694-700, July/Aug. 1991

[16] W. L. Erdman and R. G. Hoft, "Induction machine field orientation along airgap and stator flux," IEEE Trans. Energy Conversion, vol. 5, pp. 115-121, Mar. 1990.

[17] C. J. Francis, H. Z. de la Parra, and K. W. E. Cheng, "Practical implementation of a stator flux oriented control scheme for an induction machine," in Proc. 5th Int. Conf. Power Electronics and Variable-Speed Drives, 1994, pp. 54-59.

[18] A. Gastli, T. Takeshita, and N. Matsui, "A new stator-flux-oriented speed-sensorless control algorithm for general purpose induction motor drive," Trans. Inst. Elect. Eng. Jpn. D, vol. 114-D, no. 1, pp. 9-16, Jan. 1994.

[19] T. G. Habetler, F. Profumo, G. Griva, M. Pastorelli, and A. Bettini, "Stator resistance tuning in a stator flux field oriented drive using an instantaneous hybrid flux estimator," in Proc. 5th European Conf. Power Electronics and Applications, 1993, vol. 4, pp. 292-299.

[20] X. Xu and D. Novotny, "Selection of the flux reference for induction machine drives in the field weakening region," IEEE Trans. Ind. Applicat., vol. 28, pp. 1353-1358, Nov./Dec. 1992.

[21] H.-S. Mok, J.-S. Kim, Y.-R. Kim, and M.-H. Park, "A stator flux oriented speed control of induction machine without speed sensor," in Proc. 4th European Conf. Power Electronics and Applications, 1991, vol. 4 , pp. $678-682$.

[22] F. Profumo, M. Pastorelli, P. Ferraris, and R. W. De Doncker, "Comparison of universal field oriented (UFO) controllers in different reference frames," in Proc. 4th European Conf. Power Electronics and Applications, 1991, vol. 4, pp. 689-695.

[23] Y. Xue, X. Xu, T. G. Habetler, and D. M. Divan, "A low cost stator flux oriented source variable speed drive," in Conf. Rec. 1990 IEEE-IAS Annu. Meeting, 1990, vol. 1, pp. 410-415.

[24] P. Thogersen and J. K. Pedersen, "Stator flux oriented asynchronous vector modulation for ac-drives," in Conf. Rec. 21st Annu. IEEE Power Electronics Specialists Conf., 1990, pp. 641-648.

[25] C. R. Sullivan and S. R. Sanders, "Models for induction machines with magnetic saturation of the main flux path," IEEE Trans. Ind. Applicat., vol. 31, pp. 907-917, July/Aug. 1995

[26] G. B. Kliman, R. A. Koegl, W. J. Premerlani, and T. B. Breen, "A demonstration of a sensorless torque meter for ac motors," in Conf. Rec. 31st IEEE-IAS Annu. Meeting, 1996, pp. 633-637.

[27] J. D. Lambert, Numerical Methods for Ordinary Differential Systems New York: Wiley, 1991.

[28] W. Leonhard, Control of Electrical Drives. New York: SpringerVerlag, 1985, 1990.

[29] R. S. Colby, A. K. Simlot, and M. A. Hallouda, "Simplified model and corrective measures for induction motor instability caused by PWM inverter blanking time," in Conf. Rec. 21st Annu. IEEE Power Electronics Specialists Conf., 1990, pp. 678-83.

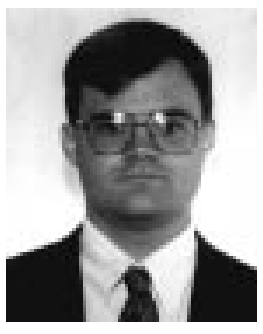

Heath Hofmann (S'94) was born in Texas in 1969 $\mathrm{He}$ received the B.S. degree in electrical engineering from the University of Texas, Austin, in 1992. He is currently working toward the Ph.D. degree at the University of California, Berkeley.

He has published technical papers on power distribution systems, induction machine control, and the design of synchronous reluctance machines. His research interests include the simulation, design, and control of power electronics circuits and electrical machinery. 


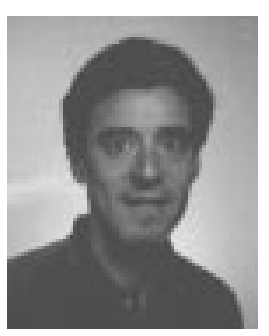

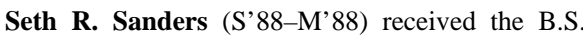
degrees in electrical engineering and physics and the M.S. and Ph.D. degrees in electrical engineering from Massachusetts Institute of Technology, Cambridge, in 1981, 1985, and 1989, respectively.

From 1981 to 1983 , he was a Design Engineer with the Honeywell Test Instruments Division, Denver, CO. Since 1989 , he has been a faculty member in the Department of Electrical Engineering and Computer Sciences, University of California, Berkeley, where he is currently an Associate Professor. During the 1992-1993 academic year, he was on industrial leave with National Semiconductor, Santa Clara, CA. His research interests are in high-frequency power conversion circuits and components, variable-speed ac motor drive systems, simulation, and nonlinear circuit and system theory as related to the power electronics field.

Dr. Sanders was the recipient of the National Science Foundation Young Investigator Award in 1993 and has served as Chair of the IEEE Technical Committee on Computers in Power Electronics.

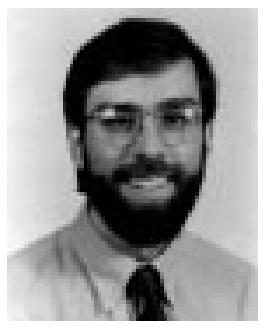

Hanover, NH.
Charles R. Sullivan (S'92-M'96) was born in Princeton, NJ, in 1964. He received the B.S. degree from Princeton University, Princeton, NJ, in 1987 and the Ph.D. degree from the University of California, Berkeley, in 1996, both in electrical engineering.

From 1987 to 1990, he was with Lutron Electronics, Coopersburg, PA, developing highfrequency dimming ballasts for compact fluorescent lamps. He is currently an Assistant Professor in the Thayer School of Engineering, Dartmouth College, 